\title{
New Evidence of Regional Geological Structures Inferred from Reprocessing and Resistivity Data Interpretation in the Chingshui-Sanshing-Hanchi Area of Southwestern Ilan County, NE Taiwan
}

\author{
Gong-Ruei Ho ${ }^{1}$, Ping-Yu Chang ${ }^{2}$, Wei Lo ${ }^{3, *}$, Chia-Mei Liu ${ }^{4}$, and Sheng-Rong Song ${ }^{5}$ \\ ${ }^{1}$ Graduate Institution of Engineering Technology-Doctoral, National Taipei University of Technology, Taipei, Taiwan \\ ${ }^{2}$ Institute of Applied Geosciences, National Taiwan Ocean University, Keelung, Taiwan \\ ${ }^{3}$ Department of Materials and Mineral Resources Engineering, National Taipei University of Technology, Taipei, Taiwan \\ ${ }^{4}$ Department of Geology, Chinese Culture University, Taipei, Taiwan \\ ${ }^{5}$ Department of Geosciences, National Taiwan University, Taiwan
}

Received 9 April 2013, revised 23 January 2014, accepted 24 January 2014

\begin{abstract}
The Ilan Plain is located at the southwestern tip of the back arc basin of the Okinawa Trough, which propagates westward into the Taiwan orogen. A long discussed issue concerns whether the opening normal-fault system of the Okinawa Trough propagates and transforms into the thrust-fault system of the Taiwan orogen. We have reprocessed and inverted resistivity measurements from a series of surveys conducted in the 1970s around the Chingshui-Sanshing-Hanchi area of southwestern Ilan County. The 2D and 3D inverted resistivity images reveal the regional structures. A major conductive structure dipping toward the northwest at an angle of $30^{\circ}-40^{\circ}$ is located at the expected site of the Niudou Fault separating the Early Miocene Szeleng and Kangkou Formations from the Lushan Formation in the Sanshing area, which dip direction of two conductive structures with a dipping angle of $50^{\circ}-70^{\circ}$ were coinciding with the dip direction of normal faults identified from the field surveys. In addition three high-angle discontinuity structures, dipping toward the north with an angle of $60^{\circ}-80^{\circ}$ can be identified in the resistivity profile along Hanchi. We tend to suggest these structures as the extended portions of the normal faults that have been identified under the unconsolidated sediments in the Ilan Plain. Resistivity profiles from the Chingshuichi area reveal the existence of the vertical Chingshuichi, the Dachi, and the Xiaonanauo Fault. Hot springs were found in the junction area of the Chingshuichi and the Xiaonanauo Fault. The junction region of these two fault systems is the potential Chingshui geothermal field that provides fluid geothermals from the deep.
\end{abstract}

Key words: Ilan Plain, Geothermal field, Resistivity profiles

Citation: Ho, G. R., P. Y. Chang, W. Lo, C. M. Liu, and S. R. Song, 2014: New evidence of regional geological structures inferred from reprocessing and resistivity data interpretation in the Chingshui-Sanshing-Hanchi area of southwestern Ilan County, NE Taiwan. Terr. Atmos. Ocean. Sci., 25, 491-504, doi: 10.3319/TAO.2014.01.24.01(TT)

\section{INTRODUCTION}

The Ilan Plain is located at the southwestern tip of the back arc basin of the Okinawa Trough, which propagates westward into the Taiwan Orogen (e.g., Lee et al. 1980; Sibuet et al. 1987; Sibuet et al. 1998). An interesting issue here concerns whether the opening normal-fault systems of the Okinawa Trough propagate and transform into the thrust-fault systems of the Taiwan orogen.

Although we have many studies on structural models

\footnotetext{
* Corresponding author

E-mail:lowei93@ntut.edu.tw
}

about the Ilan Plain (e.g., Ho 1975; Su 1978; Hsiao and Chiang 1979; Hsu et al. 1996; Lee et al. 1997; Deffontaines et al. 2001; Tong 2008; Chen 2013), information regarding the fault system is extremely limited because many outcrops were covered by unconsolidated alluvial deposits. Therefore, there are plenty of fault reports with different fault descriptions. Most people think that it is a normal fault systems characterized by a series of sub-parallel thrust faults during Plio-Pleistocene mountain building and later on some areas affected by recent normal faulting due to the opening of the offshore Okinawa trough. (e.g., Wu and Chang 1976; Tseng 1978; Shyu et al. 2005) However, several reviews that the 
most prominent long-term geological faults in this area are mountain-building-related reverse faults (e.g., Chiang 1976; Lin and Lin 1995). There are still many questions to be clarified because most of these fault characteristic are under unconsolidated deposits. For this reason, we have compiled previous studies of fault outcrops in Fig. 1 and reprocessed resistivity measurements from a series of surveys conducted nearly 40 years ago in the Chingshui-Sanshing-Hanchi area of southwestern Ilan Plain (Fig. 2).

From 1973 - 1975 the Industrial Technology Research Institute (ITRI) conducted geophysical reconnaissance surveys in this area (Lee 1994) in order to evaluate the geothermal reservoir. Some of these resistivity surveys involved a large electric power output, large dipole lengths (300 - $1000 \mathrm{~m}$ ), and large electrode separation lengths (greater than $300 \mathrm{~m}$ ). These large-dipole, long-distance (LLD) resistivity surveys were of two types: one was conducted along lines from $3-10 \mathrm{~km}$, as being common in traditional two-dimensional resistivity methods. The other was conducted based on the orthogonal bipole-bipole method, in which the receiver dipole is moved across the survey area while the dipole direction is kept normal in relation to the source dipole. According to the survey report, the data were collected in a collinear dipoledipole electrode configuration along three survey lines in the Sanshing and Hanchi areas, and in orthogonal bipole- bipole configurations across the Chingshui area. The LLD dipole-dipole resistivity surveys were conducted with a signal output of 1000 Volts from 3 - 13 Amps along the 4.5-km ST line and the 6-km LT line from Sanshing in the Ilan Plain into the Hsuehshan Range with an electrode separation of $300 \mathrm{~m}$ and along the 10-km HT line from Hanchi to Ding LiuJe in the Ilan Plain (Fig. 2) with an electrode separation of $500 \mathrm{~m}$. Both ST and LT lines across the Lanyangchi River, have a length of $300 \mathrm{~m}$ for the transmitter and receiver dipoles. The HT survey utilized the transmitter and receiver dipole lengths of $500 \mathrm{~m}$ for the dipole-dipole measurements. These LLD resistivity surveys were conducted across the boundaries between the Central/Hsuehshan Ranges and the southwestern tip of the Ilan Plain, and provided important information on evaluating geological structures with a depth of over one to two kilometers between the orogen system and the back arc basin of the Okinawa Trough.

Conducting LLD surveys require a team with 6 - 8 crew members and are time consuming. It is also difficult to reproduce the LLD surveys with modern automatic resistivity systems because of the limited power output due to safety issues. In addition, the growing population and the expansion of human activities in the potential geothermal area hampered efforts to conduct LLD resistivity surveys with a high-power output. Hence, the old LLD measurements were
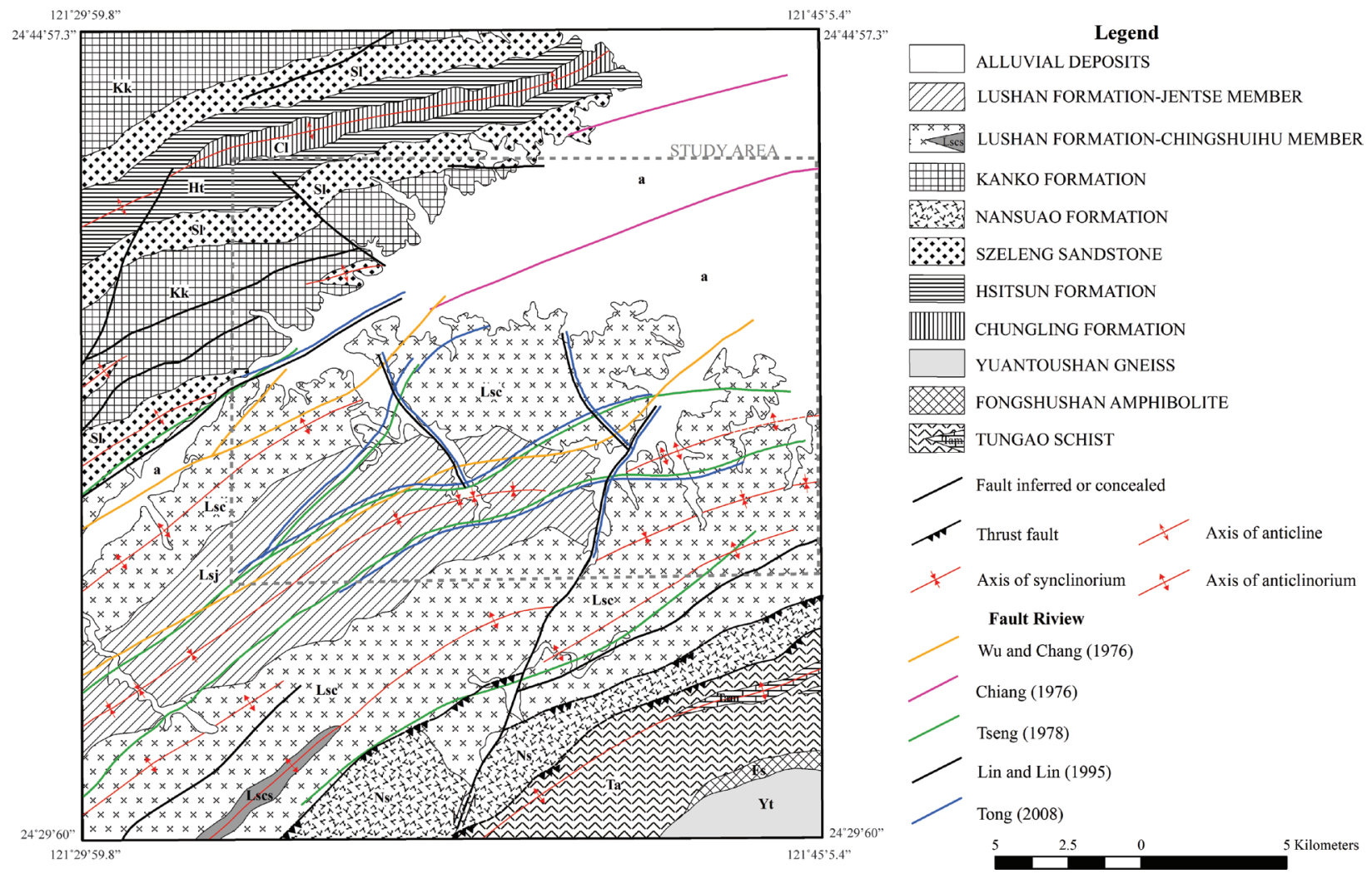

Fig. 1. The previous fault characteristics and locations review study: the orange line is published by Wu and Chang (1976); the pink line is published by Chiang (1976); the green line is published by Tseng (1978); the black line is published by Lin and Lin (1995) and the blue line is published by Tong (2008) with different symbols form normal and reverse fault. The geological map is redrawn from Lin and Lin (1995). 


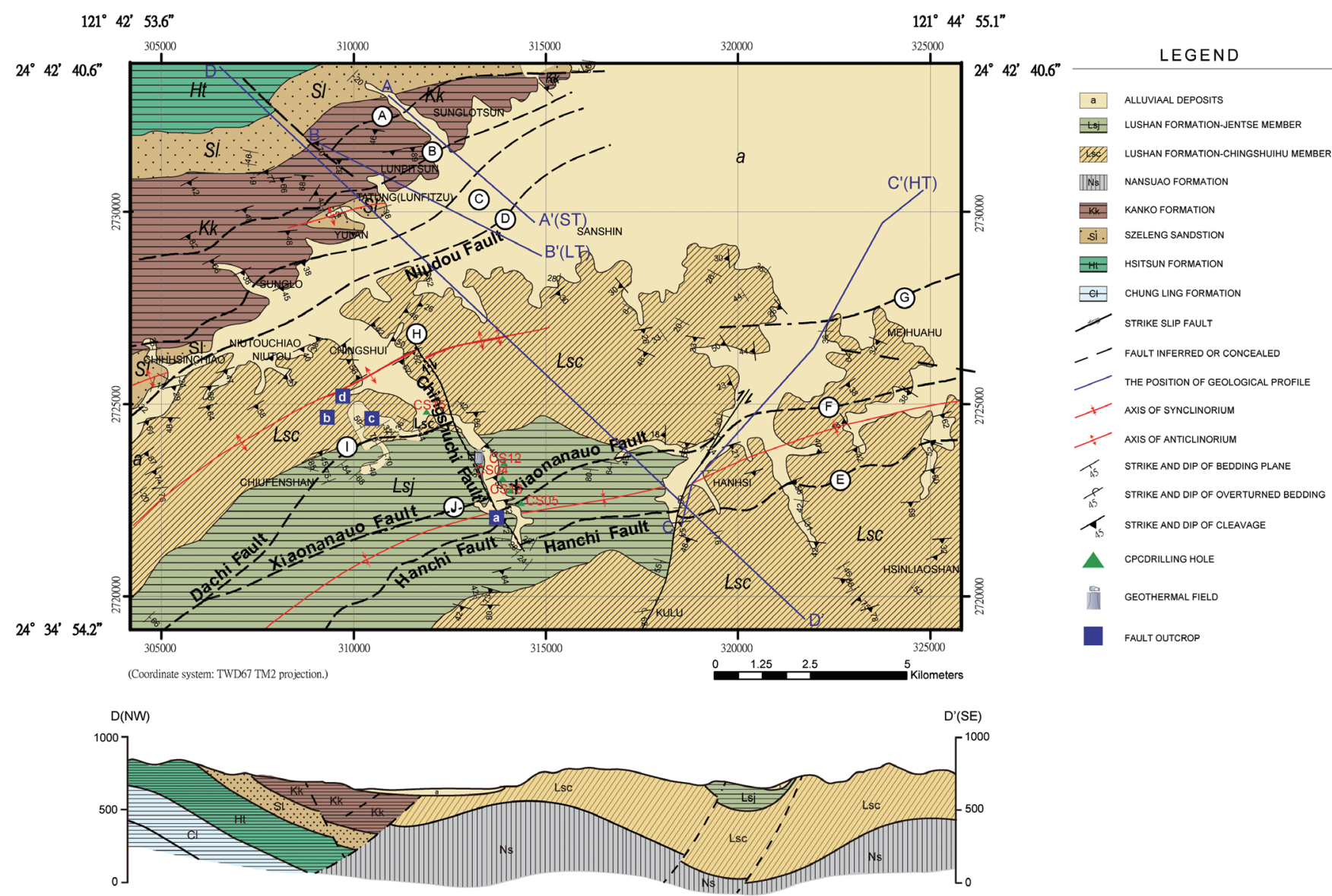

Fig. 2. The geological map and locations of the LLD survey lines ST (the A - A' profile), LT (the B - B' profile), and HT (the C - C' profile), as well as the survey area of the orthogonal bipole-bipole surveys in the study area. The locations of the Chingshui geothermal field, fault outcrops and the Chinese Petroleum Corporation drilling wells are located on the dashed line A - J which shows possible fault plane by the inverted resistivity profiles and the geological profile explanation.

precious data pertaining to the geological structures in the Chingshui area. Recent innovations in computer-resolution power enabled us to invert these old data with state-of-theart inversion codes and provide resistivity models that could not have been acquired 40 years ago. In this paper we present interpretation on inverted images of the LLD resistivity measurements in the Chingshui-Sanshing-Hanchi area.

\section{GEOLOGICAL SETTING}

The Ilan Plain is thought to have taken shape from the extension of the back arc basin of the Okinawa Trough within the Eurasian continental lithosphere (Lai et al. 2009). The recent extension of the Okinawa Trough stands from approximately $0.1 \mathrm{Ma}$ involved ENE- and WSW-trending normal faults dipping toward the Okinawa Trough axis with offsets of a few meters to tens of meters (Sibuet et al. 1998; Lai et al. 2009) in the westernmost part of the trough. Unconsolidated alluvial deposits from the Lanyangchi River were laid over the rock basement which exhibits faults (A - D in Fig. 2; Lin and Lin 1995). Previous studies have identified
ENE-trending faults beneath the unconsolidated deposits by means of seismic reflection and refraction images and magnetic anomaly analysis around the Ilan Plan (Chiang 1976; Hsu et al. 1996; Deffontaines et al. 2001; Chen 2013).

The Lishan Fault is extended from the Niudou Fault which separates the Hsuehshan Range from the Central Range and has previously been interpreted as a backthrust being reactivated as normal faulting (Ho 1975; Lee et al. 1997). The fault separates the Oligocene sandstone and the slate of the Hsuehshan Range in the west from the Miocene slate of the Central Range in the east. In this paper we can also identify that from the western Szeleng sandstone and the eastern Lushan formation-chingshuihu member (structure-D in Fig. 2). Lin and Lin (1995) also presents some fault outcrops on the Niudou bridge and Fanfan river which show evidence of a strong deformed fault zone of the Niudou fault.

The Chingshui-Sanshing-Hanchi area, one of Taiwan's largest existing productive geothermal fields (Fig. 2) (Lee 1994), is located just south of the junction belt of the Hsuehshan and the Central Ranges. The rocks in this area consist of dark-grey and black slate. Regionally, stratigraphy from top 
to bottom is the Lushan Formation, Nansuao Formation in the east area of Niudou Fault; Kanko Formation, Szeleng Sandstone, Hsitsun Formation, and Chungling Formation in the west area of Niudou Fault. We also compiled drilling reports from the Chinese Petroleum Corporation from 1976 - 1984 in the Chingshui area (Fig. 3). Based on these subsurface geological reports and field investigations, the Miocene Lushan Formation can be divided into the upper Jentse Member consisting of mainly dark-grey slate CS_4, CS_5, CS_12, and CS_13, and the lower Chingshuihu Member composed of alternation of argillite and meta-sandstone CS_15. The Chingshuihu Member conformably overlies the Nansuao Formation composed of slate, occasionally intercalated with thin beds of fine-grained sandstone. To the west, the Chungling Formation is mainly composed by argillite and slate. The Kanko Formation consists of argillite and metasandstone. The Szeleng Sandstone is composed mainly of thick-bedded, gray to grayish white, medium- to coarse-grained quartz metasandstone. The Hsitsun Formation consists mainly of alternations of silty argillite and fine-grained metasandstone, thick-bedded argillite or slate with thin bedded metasandstone intercalation (Huang and Peng 1976; Chou et al. 1977; Fan 1978; Torng and Young 1978; Lee 1984).

The study area is constituted by two regional folds according to the vergence from minor folds in the thin-bedded of sandstone (Fig. 2). The synclinorium axis is located within the Jentse member across the upstream region of the Chingshuichi River. The anticlinorium axis is located across the downstream region of Chingshuichi in the Chingshuihu member. Both of fold axis were offset by the Chingshuichi Fault.

Several NE-trending normal $60^{\circ}-70^{\circ} \mathrm{SE}$ dipping faults were reported in the area, including the Dachi, the Xiaonanauo, and the Hanchi Fault (Tseng 1978; Lin and Lin 1995) (Fig. 2). The geothermal field is thought to follow the surface trace of the suspected Chingshuichi Fault along the Chingshuichi Valley (Su 1978; Hsiao and Chiang 1979; Tong et al. 2008). The Jentse member crops out in the Chingshui hot spring region. Lin and Yang (1999) proposed that the normal faults in the area were formed during the Pengli Orogeny in the Late Pliocene. We can also find some outcrops along the Chingshuichi and Dachi rivers (Fig. 4). There are high angle normal faults with fault gouge and slickenside around the Dachi fault and the Hanchi fault. In order to clarify the formations from the Hsuehshan terrain to the Central Ranges, we integrated survey results as four profiles which cross the Chungling, Hsitsun, Szeleng, Kanko, Nansuao, Lushan Formations, and the normal faults (Fig. 2: A - A', B - B', C - C', and D - D'). However, some outcrops of other faults cannot be found on the surface after heavy weathering and erosion in the area. In order to evaluate these structures we studied the resistivity images around this region.

\section{DATA PROCESSING AND INVERSION}

During the 1973 - 1975 surveys the collinear dipoledipole measurements were collected by increasing the

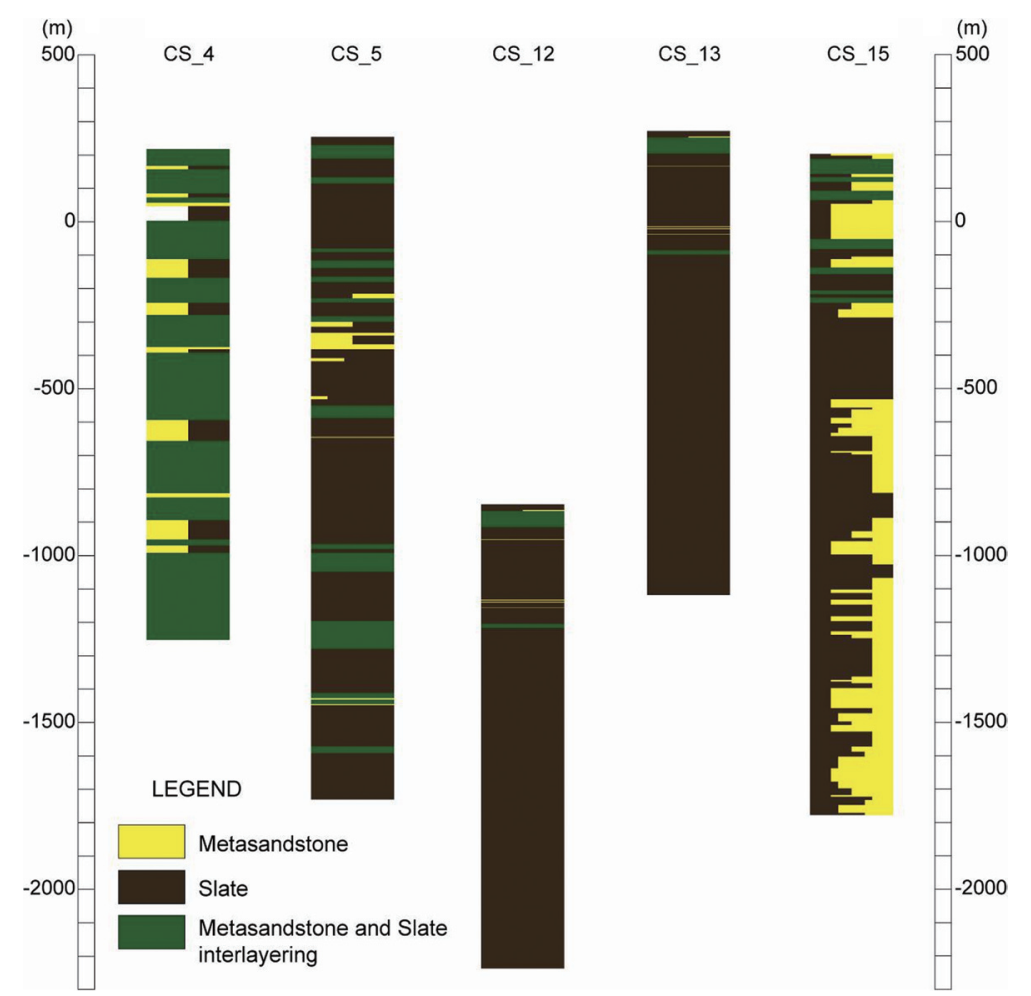

Fig. 3. The compiled Chinese Petroleum Corporation drilling reports from 1976 - 1984 in Chingshui area. 

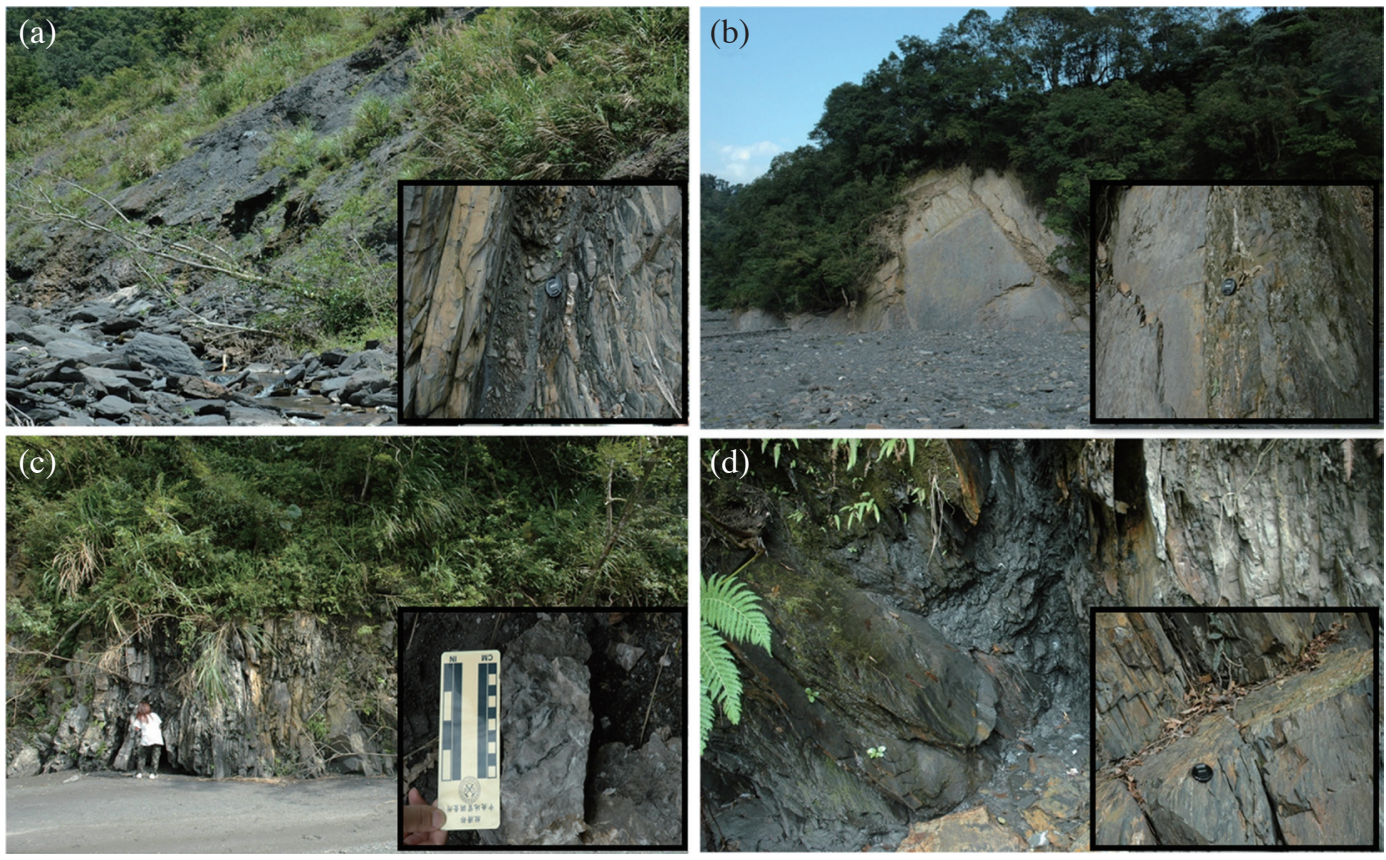

Fig. 4. The outcrops of Dachi and Hanchi fault. (a) The fault breccia at the Hanchi fault with a steep fault plane. (b) The fault slickenside and fault plane of Dachi fault. This fault strike NE, and where the Chingshuihu member is exposed on its right side and the Jentse member on its left side. (c) The noncohesive fractured slate near the Dachi fault. (d) The well developed fault gouge with fine clast size of the Dachi fault.

distance between the transmitter and receiver dipoles along the survey lines. The reciprocal data were also collected by conducting the same measurements from opposite directions along the survey lines. We combined these reciprocal data along each line into one file and used them for the inversion. We then calculated the measured data into apparent resistivity and plotted them according to the electrode positions and dipole separations to form a pseudo-section (Figs. 5a, b).

Because the old data were plotted only in pseudosections we had to digitize it in order to use the data for building the resistivity model with our inversion. We also scanned the pseudo-sections and transformed the contour plots into transparent slides (Figs. 5a, b). We overlapped the data onto the Google Earth ${ }^{\mathrm{TM}}$ map in order to locate the survey lines and the electrode positions in the current UTM system. The data were then read manually according to the contour plot and the corresponding dipole positions. Finally we performed a quality check by comparing the calculated digitized apparent resistivity values with the pseudo-section contour plots in the old records (Fig. 6).

In addition to the LLD resistivity surveys, ITRI conducted orthogonal bipole-bipole surveys by fixing the transmitter dipole at one position and moving the receiver dipole with the same separation length in the perpendicular direction across the Chingshui survey area. Using four individual transmitter locations, ITRI collected four groups of apparent resistivity datasets. This study measured each dataset with different fixed transmitter dipole positions. Figure 6 shows the maps of the calculated apparent resistivities. We per- formed the same processing procedures for digitizing the orthogonal bipole-bipole data and the quality check as that for the collinear dipole-dipole measurements.

The LLD dipole-dipole and orthogonal bipole-bipole resistivity data were inverted respectively with EarthImag$\mathrm{er}^{\mathrm{TM}}$ 2D and 3D software (AGI 2008, 2009). These two sets of software use a forward modeling subroutine and non-linear optimization techniques to calculate resistivity values. One could obtain the electrical potential fields forward solution by solving the following equation:

$\frac{\partial}{\partial x}\left(\sigma \frac{\partial V}{\partial x}\right)+\frac{\partial}{\partial y}\left(\sigma \frac{\partial V}{\partial y}\right)+\frac{\partial}{\partial z}\left(\sigma \frac{\partial V}{\partial z}\right)=I(x, y, z)$

where $V$ is the scalar electrical potential, $\sigma$ is the electrical conductivity and $I(x, y, z)$ is the electric-current source term. Dey and Morrison (1979) implemented Dirichlet and mixed-boundary conditions for solving Eq. (1). The matrix system was iteratively solved according to a conjugate gradient method. The aforementioned software also features an adjustable smooth constraint in the inversion scheme. The object function of the inversion is given by

$S(m)=\left[d_{o b s}-g(m)\right]^{T} W_{d}\left[d_{o b s}-g(m)\right]+\alpha \cdot m^{T} R m$

where $m$ is the model parameter, $d_{o b s}$ is observed data, $g(m)$ is the outputs from the forward modeling function, $W_{d}$ is a diagonal matrix, $\alpha$ is a Lagrange multiplier and a 
smoothness factor and $R$ is a roughness operator. The smooth model inversion algorithm was originally described in Constable et al. (1987) and deGroot-Hedlin and Constable (1990). Without proper model smoothing to account for this sensitivity difference, the inverted model will show conductive regions congregated around the surface survey lines. Therefore, in the 2D inversion it is important to select a proper smoothing factor to help yield a reasonable inverted model in Eq. (2). We did that using trial-and-error.

There are several possible sources that may contribute errors to the digitized LLD and bipole-bipole measurements. One possible error may come from the digitizing process. The old LLD and bipole-bipole data were performed using the apparent resistivity contours in the literature. The digitized apparent resistivity of a specific electrode pair was determined with respect to its relative position to the contour lines. A new contour map was then produced with EarthImager 2D and compared with the old map to ensure consistency, as shown in Figs. 5a and b. We performed the same consistency check to the digitized bipole-bipole data. Since the contour interval is $20 \mathrm{Ohm}-\mathrm{m}$, a maximum error of $\pm 10 \mathrm{Ohm}$-m exists in the digitizing process. Hence, we estimated the digitizing errors below $16 \%$ of the measured apparent resistivity (over $60 \mathrm{Ohm}-\mathrm{m}$ ). Another possible error comes from inaccurate electrode positions. Zhou and Dahlin (2003) proved that a $10 \%$ electrode in-line position error may incur about $20 \%$ error in the inverted dipole-dipole measurement results. After overlapping the hand-drawn survey map onto the $1 / 25000$ map, we estimated that the electrode positions may have an error of $30-50 \mathrm{~m}$, and then a $10-15 \%$ uncertainty with respect to the electrode spacing may exist. We therefore estimated a position error may result in $20-30 \%$ to the inverted resistivity. The other error source is the background noise. LaBrecque et al. (1996) and Zhou and Dahlin (2003) suggested that the reciprocal errors are higher than the repetition error in representing the noise levels. Although we did not have repetition measurement records for the LLD and bipole-bipole measurements, we do have the reciprocal measurement records of the LLD surveys for the noise estimation. For the LLD surveys the mean errors from reciprocal measurements for HT, LT, and ST lines are 20.5, 4.4, and 2.0\%, respectively. The standard error deviations are 29,28 , and $24 \%$ for HT, LT, and ST surveys, respectively. Compared with the field case in Zhou and Dahlin (2003), the LLD survey noise level falls in a similar range and we judged that these digitized data are acceptable for providing reliable information about the resistivity structures in the region.

\section{RESULTS}

\subsection{The LLD Collinear Dipole-Dipole Surveys}

\subsubsection{The ST Survey Line (A - A')}

The 4.5-km ST survey line started from Sanshing and ended in the Hsuehshan Range. The inversion reached an
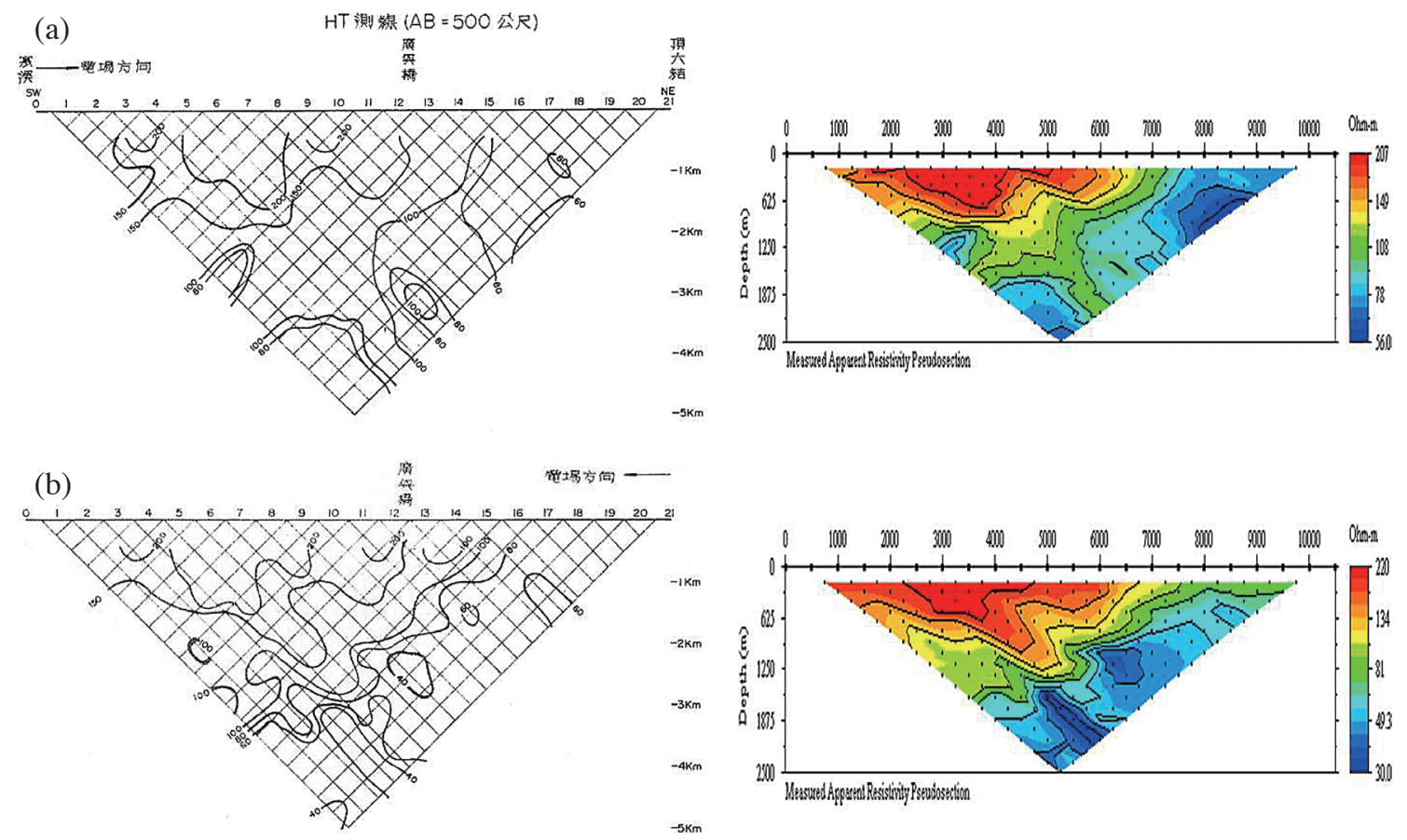

Fig. 5. (a) The contour maps of the apparent resistivity from the reciprocal HT survey measurements conducted in the 1970s. Arrows show the movement direction of the transmitter and receiver dipoles. (b) The pseudo-section of the digitized data from the reciprocal HT survey measurements in the 1970s. 

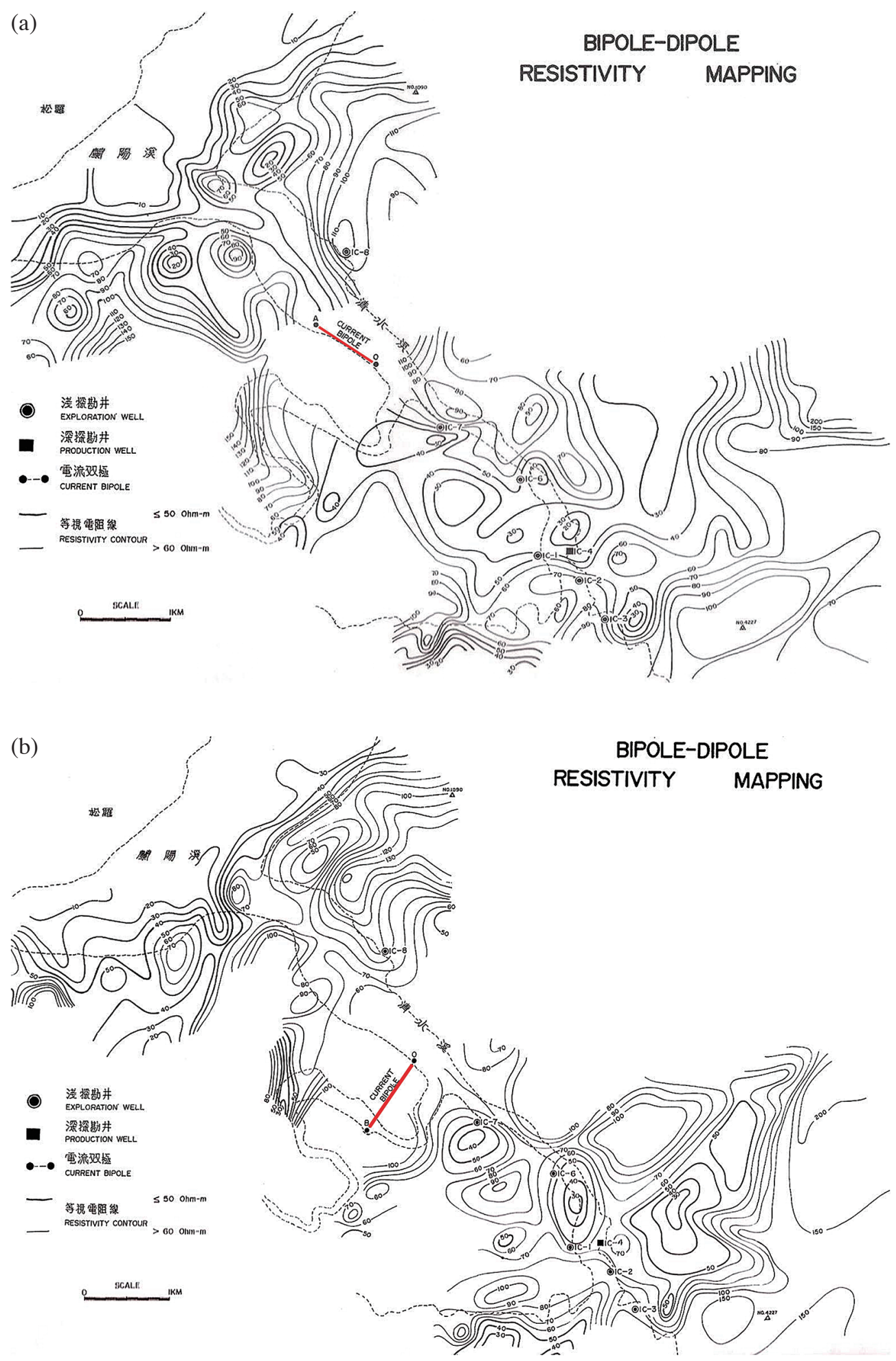

Fig. 6. The contour map of apparent resistivity from the orthogonal bipole-bipole surveys in the 1970s for fixed transmitter positions at (a) A - O and (b) $\mathrm{B}-\mathrm{O}$ on the map.

optimal solution after 9 iterations with an RMS error of $4.14 \%$ relative to the measured data. Figure 7a presents inverted images along the ST survey line and the vertical depths in the figure were converted into absolute elevations relative to the sea level. The rocks below $-600 \mathrm{~m}$ consist of conductive ma- terials with resistivity less than $70 \mathrm{Ohm}-\mathrm{m}$ in general, except for the resistive region between $3500-4000 \mathrm{~m}$ around the southeastern end of the survey line. The resistive region consists of materials with a resistivity of over $500 \mathrm{Ohm}-\mathrm{m}$ and indicates a rock composition different from those found at 
the same depth. A high-resistive rock block with resistivity of over $500 \mathrm{Ohm}-\mathrm{m}$ exists between $900-1800 \mathrm{~m}$ at depth of about -250 to $-600 \mathrm{~m}$ to the northwest of the ST line. We interpret that this high-resistive block is bounded by two linear conductive structures (A and B), dipping toward the southeast with a resistivity of less than $70 \mathrm{Ohm}-\mathrm{m}$. We also interpret another linear conductive structure C, dipping NW that is identifiable between $3000-2400 \mathrm{~m}$ to the northwest of the ST line. In addition, a large linear conductive structure, marked in Fig. 7a as structure D, dips toward the northwest at a depth between -100 and $-700 \mathrm{~m}$. A layer of the rock material within about $200-250 \mathrm{~m}$ of the surface seems to be continuous laterally with resistivity higher than $200 \mathrm{Ohm}$ $\mathrm{m}$ in general. Compared with the geological profile A - A', it also shows about $200 \mathrm{~m}$ thick Kanko formation, $400 \mathrm{~m}$ thick Szeleng formation and the underlying Hsitsun formation in the west; about $200 \mathrm{~m}$ thick Jentse member, $300 \mathrm{~m}$ thick Chingshuihu member and the underlying Nansuao formation in the east. Based on the extension of layers, we suggest stratigraphic offset exist within the A - D normal

(a)

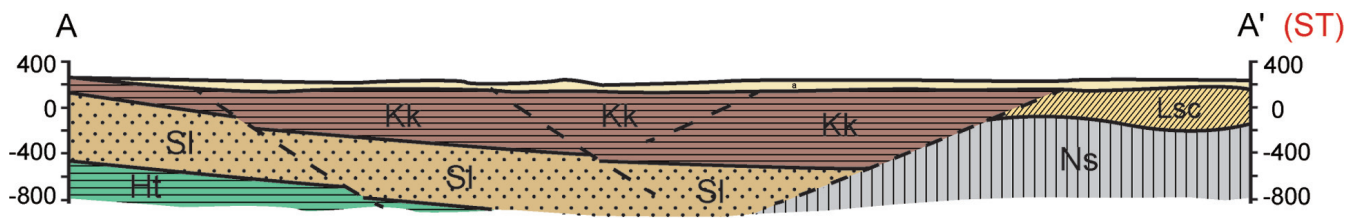

(ST)
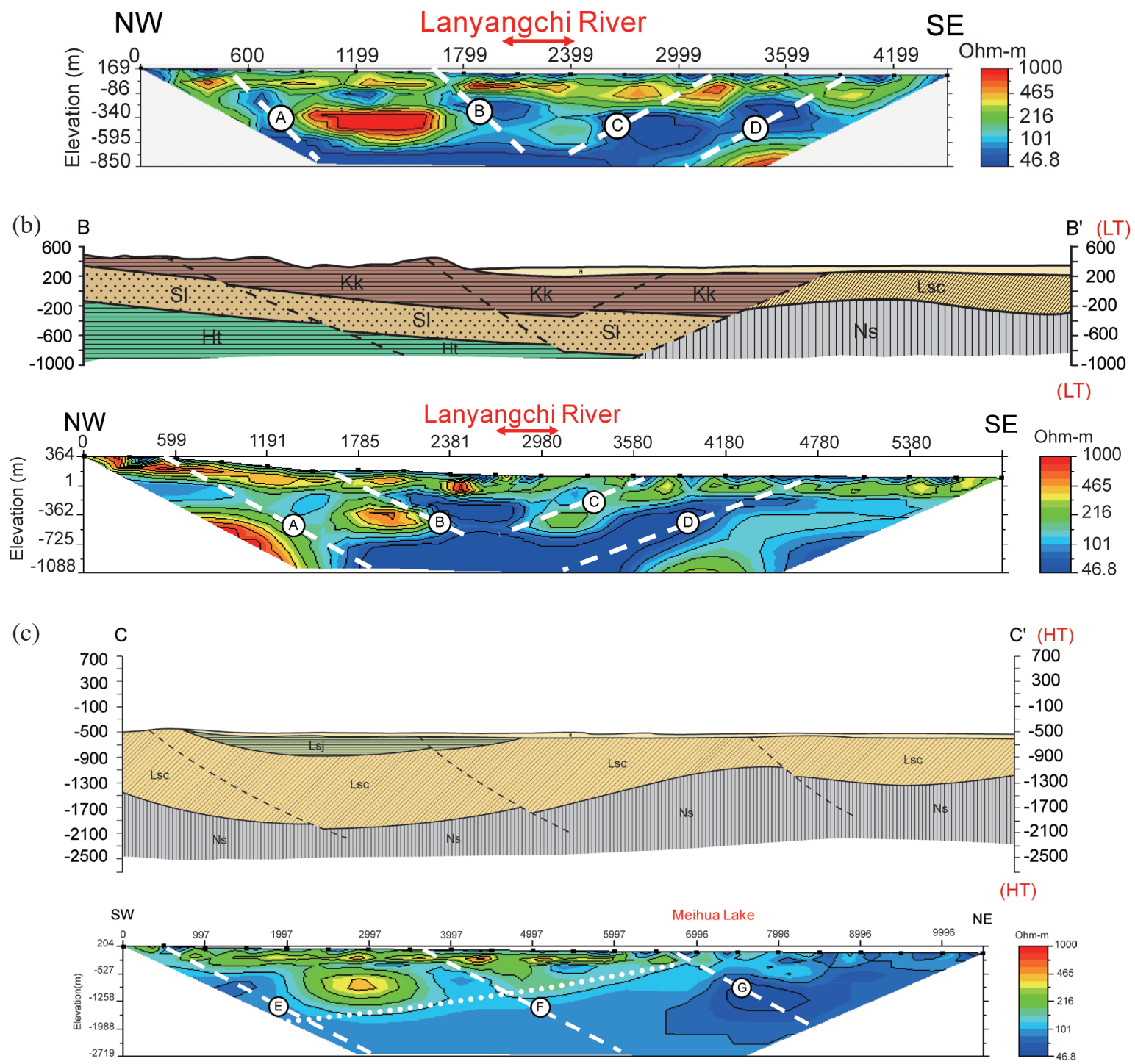

Fig. 7. The geological explanations and the inverted resistivity profiles of (a) the ST (A - A' profile), (b) the LT (B - B' profile), and (b) the HT (C-C' profile). Dashed lines (structure A - J) indicate the explanations of discontinuous resistivity structures. The horizontal and vertical axes are not at the same scale. 
faults. Since the LLD resistivity surveys utilized large dipole lengths and separations, the LLD survey inversion has poor resolution at the near-surface structures. Hence, the shallow continuous layer may suggest that the continuous layer show the effect of unsaturated soil and rock. Further, because the electrode separation of the ST line is $300 \mathrm{~m}$, it cannot effectively resolve thin layers which are depth of $100-200$ m near the ground surface.

\subsubsection{The LT Survey Line (B - B')}

The length of the LT survey line from Sanshing to the Hsuehshan Range is about $6 \mathrm{~km}$. The LT line is located in the west of the aforementioned ST line and runs nearly parallel to the ST line. The distances between the northwestern and southeastern ends of the ST and LT lines are about 1500 and $500 \mathrm{~m}$, respectively. Figure 7b shows the inverted images of LT profiles. The inversion reached an optimal solution after 6 iterations with an RMS error of $4.69 \%$ relative to the measured data. Similar to the ST line, four linear conductive structures A, B, C, and D can be interpreted. To the southeast of the conductive structure $\mathrm{D}$, a low-resistive region with about $150 \mathrm{Ohm}-\mathrm{m}$ can be found below $-700 \mathrm{~m}$. A very resistive rock with resistivity higher than $700 \mathrm{Ohm}-\mathrm{m}$ exists at -400 to $-1000 \mathrm{~m}$ depth between $600-1500 \mathrm{~m}$ from the northwestern end of the LT line. Another resistive rock block with resistivity over $350 \mathrm{Ohm}-\mathrm{m}$ existed at a depth of -250 to $-500 \mathrm{~m}$ between $1700-2300 \mathrm{~m}$. This high-resistive block is bounded by the two conductive structures A and B, which are dipping toward the southeast with a resistivity of less than $150 \mathrm{Ohm}-\mathrm{m}$. A low-resistivity region with resistivity of over $200 \mathrm{Ohm}-\mathrm{m}$ is located between $3000-3300 \mathrm{~m}$ at a depth of -250 to $-500 \mathrm{~m}$. This relatively low-resistive region is bounded by the conductive structures $\mathrm{C}$ and $\mathrm{D}$, both dip toward the northwest. We suggest that Kanko, Szeleng, Hsitsun, Lushan, and Nansuao formations are offset by A - D normal faults in the geological profile B - B'.

\subsubsection{The HT Survey Line (C - C')}

Figure 7c shows the inverted image of the HT line. The HT line is the longest survey line (about $10 \mathrm{~km}$ ) among the LLD surveys in the area with an electrode separation of $500 \mathrm{~m}$. The HT line extends northward from Hanchi to DingliuJe near Luodong. In general at shallow part of upper $1 \mathrm{~km}$, rocks are more resistive at the southwestern part (over $150 \mathrm{Ohm}-\mathrm{m}$ ) than the rocks at the northeastern part (less than $100 \mathrm{Ohm}-\mathrm{m}$ ) of the HT line. The resistivity becomes lower toward the depth. The transition from 150 to $100 \mathrm{Ohm}-\mathrm{m}$ seems to be a nearly horizontal plane that dips gently toward the southwest. In addition, we can observe two conductive lobes, $\mathrm{E}$ and $\mathrm{F}$, with resistivity less than $100 \mathrm{Ohm}-\mathrm{m}$ intruding into the higher resistive regions. Both $\mathrm{E}$ and $\mathrm{F}$ structures dip toward the northeast, and their surface outcrops are consistent with the Xiaonanauo and Hanchi faults, which were mapped by field survey and identified in previous studies (e.g., Tseng 1978). Furthermore, a conductive region with a resistivity of less than $50 \mathrm{Ohm}-\mathrm{m}$ is located between $7500-8500 \mathrm{~m}$ at a depth of -500 to $-1500 \mathrm{~m}$. This conductive region seems to be dipping toward the north, as represented by structure $\mathrm{G}$ in Fig. 7. Profile C - C' shows that Lushan formation (including Jentse Member and Chingshuihu Member) of the least $1200 \mathrm{~m}$ thickness, the underlying Nansuao Formation. Furthermore, the three conductive structures $\mathrm{E}, \mathrm{F}$, and $\mathrm{G}$ seem to have a similar dip angle toward the northeast.

\subsection{The Orthogonal Bipole-Bipole Surveys}

Based on the 3-D orthogonal bipole-bipole surveys, we reconstructed a 3-D model (Fig. 8a), showing two vertical slices along the east-west and the north-south directions of the inverted resistivity, together with one horizontal slice at a depth of $-1200 \mathrm{~m}$ from the 3D orthogonal bipole-bipole surveys. We achieved an optimal solution with an RMS of $16 \%$ after 8 iterations. Figure $8 \mathrm{~b}$ shows the horizontal slice that lies at a depth of $-800 \mathrm{~m}$, which overlapped onto the regional geological map. As being evidenced in Fig. 8b, we found that a major high-resistive region is located in the northwestern part of the survey area with a resistivity higher than $500 \mathrm{Ohm}-\mathrm{m}$. Moreover, this high resistive region turns into three low resistivity zones toward SE: H, I, J smaller zones at depths over $-400 \mathrm{~m}$ (Fig. 8a). In contrast, the southeastern part of the survey area shows low resistivities less than $200 \mathrm{Ohm}-\mathrm{m}$. The differences in resistivity between the northwestern part and the southeastern part correspond to two different rock formations: the Chingshuihu Member to the northwest and the Jentse Member to the southeast.

Figure $8 \mathrm{~b}$ also indicates three possible conductive structures H, I, and J. Structure $\mathrm{H}$ are located roughly along the Chingshuichi in the north-south direction. Structure I, oriented in the $\mathrm{E}-\mathrm{W}$ direction, seems to be the boundary separated the northwestern resistive and southeast conductive regions. Structure J is oriented in the SW - NE direction in the southern part of the survey area. The hot-spring spots in the Chingshui area are located in the junction area of structures $\mathrm{H}$ and $\mathrm{J}$, suggesting fractures might be important contributions for geothermal resources in the area.

\section{DISCUSSION}

A long-discussed problem is how the opening normalfault system of the Okinawa Trough has propagated, transformed into the thrust-fault system of the orogen. The $2 \mathrm{D}$ and 3D inverted resistivity images from the LLD dipole-dipole and bipole-bipole surveys may reveal a few clues regarding the regional structures near the junction area of the opening Ilan plain, the Hsuehshan Range, and the Central Range. 
Combining a recent study in regional geology by Tong et al. (2008), we may obtained that the bulk resistivity of regional meta-sandstones ranges from 400 to over $500 \mathrm{Ohm}-\mathrm{m}$, and the resistivity of the argillites are mostly lower than $300 \mathrm{Ohm}-\mathrm{m}$. In general, the fault zones filled with fluids and weathered gouge will result in very conductive responses in the resistivity measurements. As a result, we attempt to characterize the rock types and geological structures with the resistivity differences and limited outcrops. In the inverted LLD images, both ST and LT images show that a major conductive structure $\mathrm{D}$, dips toward the northwest at an angle of $30^{\circ}-40^{\circ}$ (Fig. 7). The conductive structure seems to separate the north- western and southeastern resistivity blocks below $-400 \mathrm{~m}$. Previous studies (e.g., Wu and Chang 1976; Tseng 1978; Lin and Lin 1995) revealed that the Niudou Fault separated the Early Miocene Szeleng and Kangkou Formations from the Chingshuihu Member of the Lushan Formation along the Lanyangchi River in the southeastern part of the LT and ST lines (Fig. 2). We postulate that the conductive structure $\mathrm{D}$ is most likely an extension of the Niudou Fault because of geometric similarities between resistivity images and surface geology. However, further investigation such as seismic exploration is still needed to verify this tentative interpretation (e.g., Chen 2013). To the northwest of this low-angle conductive
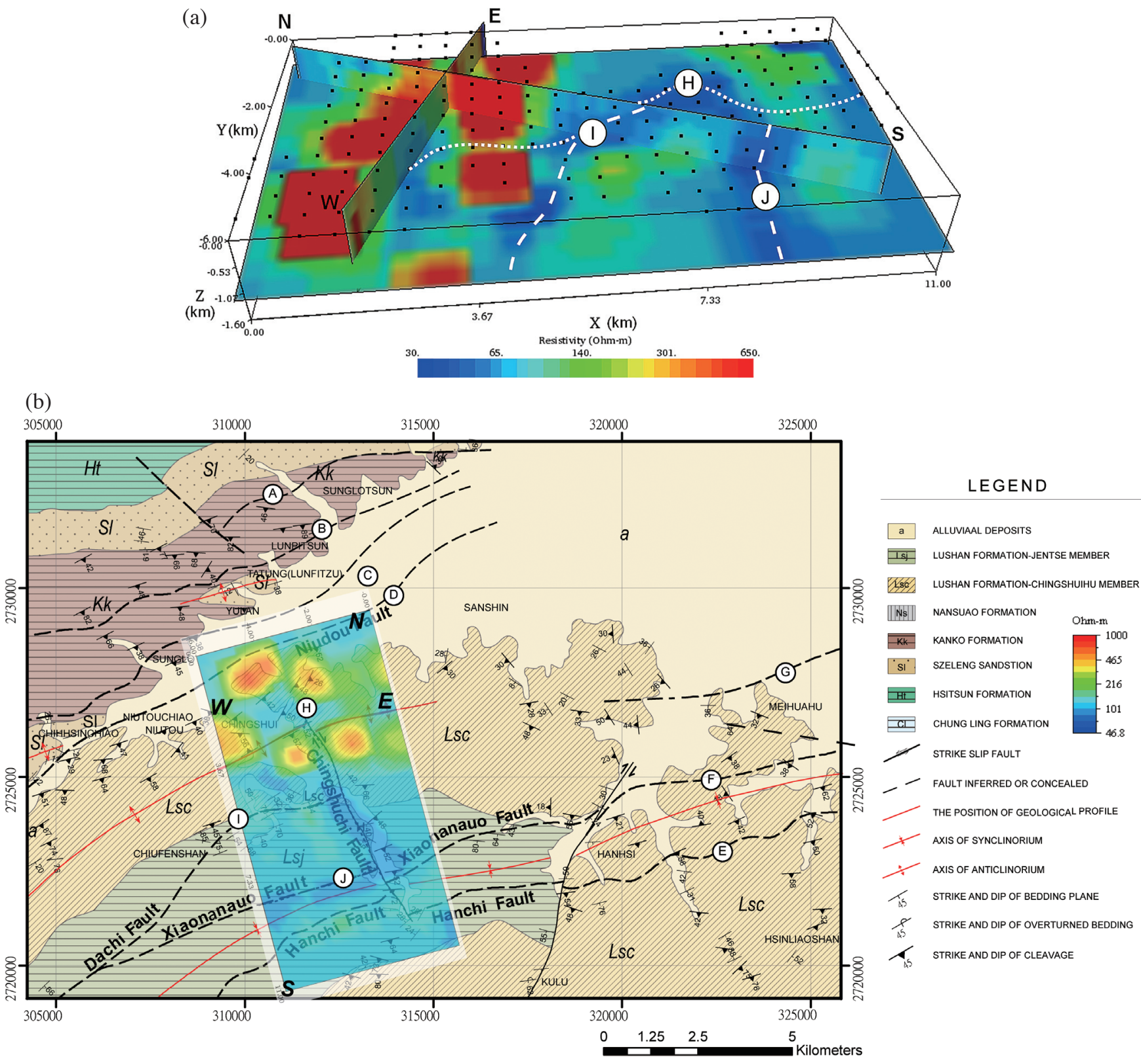

Fig. 8. (a) The inverted results of the orthogonal bipole-bipole surveys. The two vertical slices show the resistivity profiles along the $\mathrm{N}-\mathrm{S}$ and $\mathrm{E}-\mathrm{W}$ directions. The horizontal slice is at a depth of $-1200 \mathrm{~m}$. Dotted line (structure-H) and dashed lines (structure-I, J) indicate the fault structures with dipping direction. (b) The resistivity horizontal slice at a depth of $-800 \mathrm{~m}$, overlapping onto the geological map. 
structure below the $\mathrm{D}$ dashed line a high-resistive region is observable below $-400 \mathrm{~m}$ in the deeper LT profile. Above this resistive region there lies a relative conductive layer with resistivity less than 200 Ohm-m. Because the Szeleng Sandstone at the anticline hinge is located in the nearby area, we interpret that the high resistive region may represent the resistive Szeleng Sandstone and that the overlaid relatively conductive rock may be part of the Kanko Formation ( $\mathrm{Wu}$ and Chang 1976; Tseng 1978). From the LLD images of the ST and LT lines, we also deduced two conductive structures, $\mathrm{A}$ and $\mathrm{B}$, with a dipping angle between $50^{\circ}-70^{\circ}$. The orientations and positions of structures $\mathrm{A}$ and $\mathrm{B}$ coincide with the extended direction of normal faults identified from various field surveys (Wu and Chang 1976; Tseng 1978; Lin and Lin 1995) and from neo-tectonic explanations based on geomorphic features in DEM (Shyu et al. 2005). Structure C, on the other hand, is a relatively small structure that dips toward the northwest and may be a normal fault associated with the opening of the Ilan Plain. However, these structures could be the older reverse fault and possible normal fault reactivation on the previous structures. There are also few reverse faults report near structure $\mathrm{A}, \mathrm{B}$, and $\mathrm{C}$ with inferred outcrops or profiles (Chiang 1976; Lin and Lin 1995). We compiled all the previous fault studies around Chingshui-SanshingHanchi area in Fig. 1 for better comparison with different characteristics and locations. Since there are no observable outcrops for the normal or reverse faults in the Ilan Plain, the Lanyangchi River is located between B and C structures and implies that its channels are situated in the depressed graben of the normal faults. Furthermore, the orientation of the graben is consistent with the deepest axis of the rock basement found by the seismic exploration (Chiang 1976; Zhang 2010) under the middle and lower Ilan Plain. This axis is thought to be correlated to the extension center of the Okinawa Trough between 0.1 - $2 \mathrm{Ma}$ (Kang et al. 2008). Although the structures from surface or subsurface of the Ilan plain was still not clear, there are 19 seismic reflection profiles and 25 core borings has been reported to reveal the subsurface structure beneath the Ilan Plain (Chen 2013). The structure was mainly formed by two sets of normal faults which can be related to our structure A, B, C, and D. In Fig. 7, the structures A, B, and $\mathrm{C}$ extend deeper and join structure $\mathrm{D}$ into a massive conductive structure, which divides the resistive rocks in the northwest from the less resistive ones in the southeast. A probable explanation is that the deep conductive structure represents the previous Lishan fault between the Miocene Hsuehshan formations and the slaty Lushan rocks. The geometry of the conductive structures implies that the relative young normal faults are developed on the old Lishan Fault zone that separating Hsuehshan and the Lushan rock formations.

In the HT profile we show a transition separating the high-resistive rocks (over $150 \mathrm{Ohm}-\mathrm{m}$ ) from the low-resistive rocks (less than $100 \mathrm{Ohm}-\mathrm{m}$ ) dips toward the southwest at an angle of $22^{\circ}-25^{\circ}$. The transition zone has a dipping angle almost identical to the apparent dip of the bedding plane of the rocks found in the surface outcrop of Chingshuihu Member outcrops. Three high-angle discontinuous structures, dipping toward the northeast at an angle of $60^{\circ}-80^{\circ}$, are deduced from the inverted resistivity image of the HT profile. These structures, marked as E, F, and G in Fig. 2, are likely the extended portions of the normal faults that have been identified under the unconsolidated sediments in the Ilan Plain (Chiang 1976; Zhang 2010).

The inverted bipole-bipole model clarifies the regional geology structure in the Chingshui area. In the northwestern part of the survey area, the high-resistive region with resistivity higher than $500 \mathrm{Ohm}-\mathrm{m}$ is consistent with the Chingshuihu Member of the Lushan Formation, shown in Fig. 8b. Moreover, we found that the high-resistive regions are separated into two sub-regions below $-400 \mathrm{~m}$, with both dip directions parallel to the dip directions of the Chingshuihu Member, as noted in Tseng (1978). This finding supports an anticline structure between the two sub-regions, as in the geological map of Lin and Lin (1995). The conductive structure $\mathrm{H}$ along the Chingshuichi is likely to be the Chingshuichi Fault described in the previous studies (e.g., Tong et al. 2008). The southern part of the bipole-bipole survey area consists of rock with resistivity less than $200 \mathrm{Ohm}-\mathrm{m}$ and is likely the Jentse Member of the Lushan Formation. Structure I dipping northwest separates the Chingshuihu Member and the Jentse Member. This conductive structure (structure I) was identified in the gravity-anomaly maps as well (Tong et al. 2008) and previously named the Dachi Fault by Tseng (1978). Yet this Dachi Fault was not recognized in the geological map later presented by Lin and Lin (1995). The vertical conductive structure J, trending NE - SW with a subvertical NE dipping angle passes through the Jentse Member in the southern survey area. The J structure is located on the aforementioned Xiaonanauo Fault in Tseng (1978). However, the same structure was explained as a syncline axis in Lin and Lin (1995). With the geometry of the conductive structure we concluded that the $\mathrm{J}$ structure likely represents the Xiaonanauo Fault. In Fig. 2 the I and J structures seem to stop at the Chingshuichi Fault. Note that the conductive $\mathrm{J}$ structure seems to be on the extended direction of the $\mathrm{F}$ structure in the HT profile. This finding could imply that the two structures, F and J, are probably the same fault with a dip toward the northwest. Owing to the lack of observations in the eastern part of the Chingshuichi Fault (structure H), it remains unclear whether the two conductive structures, I and J, terminate at the Chingshuichi Fault or not.

Based on these new observations from the resistivity surveys we are able to improve the regional geological map of Tseng (1978) and Lin and Lin (1995), and have further interpretations for the major structures in this area (Fig. 2). Figure 7 shows the geological interpretations with the resistivity images of ST, LT, and HT profiles. The Lishan/ Niudou Fault is a major ancient thrust fault that separates 
the rock formations in the Hsuehshan Range from the Lushan Formation. Normal faults resulting from the Ilan Plain opening can be observed in the LT and ST profiles. From the two profiles LT and ST, we are able to depict the strikes and dips of the individual normal fault in the system. The axis of the opening normal faults is inconsistent with the location of the Niudou fault. In addition, the normal faults can also be observed in the HT cross-section. We also observed that an oblique distinctive surface (the white-dotted line in HT profile) separates the high-resistive Lushan Formation from the Nansuao Formation under the Ilan plain. Since no other evidence shows the existence of thrust fault and the transition zone has a similar apparent dip to the measurements in the regional Lushan Formation, we interpret it as a compatible surface between the Lushan Formation and the underlying Nansuao Formation.

\section{CONCLUSIONS}

The ITRI conducted LLD and orthogonal bipolebipole surveys near the junction area of the opening Ilan Plain, the Hsuehshan Range and the Central Range in the 1970s. In this study, we reprocessed the ITRI's resistivity measurements conducted in the 1970s and inverted these data with modern 2D and 3D inversion codes. The 2D and 3D inverted resistivity images from the LLD dipole-dipole and bipole-bipole surveys reveal the pattern of the regional structures. Based on the LLD images of the ST and LT lines, we found two linear conductive structures, A and B, with SE dipping angles of $50^{\circ}-70^{\circ}$. The orientations and locations of structures A and B coincide with the extended portions of the normal faults identified from field surveys. Structure $\mathrm{C}$, also inferred in both the ST and LT lines, is a relatively small structure that dips toward the northwest and may be a normal fault associated with the opening of the Ilan Plain. In addition, another major linear conductive structure, D, dipping toward the northwest at an angle of $30^{\circ}-40^{\circ}$, seems to coincide with the Niudou Fault separating the Hsuehshan Range (the Early Miocene Szeleng and Kangkou Formations) from (the Lushan Formation).

Three high-angle discontinuity structures to the southeast of the Niudou fault, dipping toward the northwest at an angle of $60^{\circ}-80^{\circ}$, can be identified in the inverted resistivity image of the HT profile. These structures are likely the extended portions of the normal faults that were identified around the Chingshui geothermal area and under the unconsolidated sediments in the Ilan Plain.

The inverted bipole-bipole results clarify the regional geological structures of the Chingshui area and reveal, in particular, three vertical conductive structures, H, I, and J. Structure $\mathrm{H}$ is along the Chingshuichi and represents the location of the vertical Chingshuichi Fault. Structure I can be identified as the stratigraphic boundary between the $\mathrm{Ch}$ ingshuihu Member and Jentse Member and coincides to the Dachi Fault, proposed by Tseng (1978). The J structure trending NE - SW is likely to be the Xiaonanauo Fault. Hot springs were found in the junction area of the Chingshuichi Fault and the Xiaonanauo Fault, suggesting that faults might be the fluid conduit to provide geothermal energy.

From the resistivity surveys in Chingshui-SanshingHanchi area, we concluded that the axis of the normal faults is consistent with the depressed axis of the Okinawa Trough, which indicates that the Okinawa Trough extension propagates into the Chingshui-Sanshing-Hanchi area. The deeper massive conductive structure below the fault structures A, B, C, and D may suggest that normal faults developed in the Niudou Fault zone, which separates the Hsuehshan Range from the Lushan Formation.

In the Hanchi area we also observed a series of normal faults dipping toward the north. We observed that an oblique distinctive transition separates the resistive Lushan Formation from the Nansuao Formation under the Ilan plain. Since no other evidence shows the existence of thrust faults and the transition has a similar apparent dip to the measurements in the regional Lushan Formation, we interpret that it is a compatible surface between the Lushan Formation and Nansuao Formation in the Hanchi area. Geological maps and interpretations were modified according to our observations from the inversion images of the resistivity measurements.

Acknowledgments This work has benefited from the resistivity measurements from Industrial Technology Research Institute (ITRI) and the drilling reports have combined from Chinese Petroleum Corporation (CPC) which was instrumental for our own mapping results. In addition this paper is supported by the National Science Council of Taiwan (project number NSC-101-3113-M-002-001).

\section{REFERENCES}

AGI, 2008: Instruction Manual for EarthImager 3D version 1.5.3, Advanced Geosciences, Incorporation, Austin, Texas.

AGI, 2009: Instruction Manual for EarthImager 2D version 2.4.0, Advanced Geosciences, Incorporation, Austin, Texas.

Chen, T. C., 2013: Seismic images of the southwestern tip of the Okinawa trough - the Ilan Plain, Taiwan. Master Thesis, National Chung Cheng Univesity, Taiwan, 149 pp.

Chiang, S. C., 1976: Seismic prospecting in the Ilan Plain. Miner. Tech., 215-221. (in Chinese)

Chou, H. L., S. Y. Chang, and D. H. Peng, 1977: Subsurface Geological Report of the TIC-5 Geothermal well in the Chingshui Geothermal District, I-Lan, Taiwan Petroleum Exploration Division, 1-13.

Constable, S. C., R. L. Parker, and C. G. Constable, 1987: Occam's inversion: A practical algorithm for generating 
smooth models from electromagnetic sounding data. Geophysics, 52, 289-300, doi: 10.1190/1.1442303. [Link]

DeGroot-Hedlin, C. and S. Constable, 1990: Occam's inversion to generate smooth, two-dimensional models from magnetotelluric data. Geophysics, 55, 1613-1624, doi: 10.1190/1.1442813. [Link]

Deffontaines, B., C. S. Liu, J. Angelier, C. T. Lee, J. C. Sibuet, Y. B. Tsai, S. Lallemand, C. Y. Lu, C. S. Lee, S. K. Hsu, H. T. Chu, J. C. Lee, E. Pathier, R. F. Chen, C. T. Cheng, C. W. Liao, C. C. Lin, and H. H. Hsu, 2001: Preliminary neotectonic map of onshore-offshore Taiwan. Terr. Atmos. Ocean. Sci., 339-349.

Dey, A. and H. F. Morrison, 1979: Resistivity modeling for arbitrarily shaped three-dimensional structures. Geophysics, 44, 753-780, doi: 10.1190/1.1440975. [Link]

Fan, K. W., 1978: Subsurface Geological Report of the CPC-CS-15T Geothermal well in the Chingshui Geothermal Area, I-lan, Taiwan Petroleum Exploration Division, 1-15.

Ho, C. S., 1975: An Introduction to the Geology of Taiwan: Explanatory Text of the Geologic Map of Taiwan, Central Geological Survey, Ministry of Economic Affairs, Taiwan, 1-163.

Hsiao, P. T. and S. C. Chiang, 1979: Geology and geothermal system of the Chingshui-Tuchang geothermal area, Ilan, Taiwan. Petrol. Geol. Taiwan, 16, 205-213.

Hsu, S. K., J. C. Sibuet, and C. T. Shyu, 1996: High-resolution detection of geologic boundaries from potentialfield anomalies: An enhanced analytic signal technique. Geophysics, 61, 373-386, doi: 10.1190/1.1443966. [Link]

Huang, J. S. and D. H. Peng, 1976: Subsurface Geological Report of IC-4 well Ching-Shui, I-Lan, Taiwan Petroleum Exploration Division, 1-13.

Kang, C., T. Y. Chang, J. C. Lee, and R. F. Chen, 2008: Active tectonics in the Ilan Plain: Geological and seimological characteristics in the conjunction between the westernmost part of the Okinawa trough and the northernmost part of the Lishan fault. West. Pac. Earth Sci., 17-42.

LaBrecque, D. J., M. Miletto, W. Daily, A. Ramirez, and E. Owen, 1996: The effects of noise on Occam's inversion of resistivity tomography data. Geophysics, $\mathbf{6 1}$, 538-548. doi: 10.1190/1.1443980. [Link]

Lai, K. Y., Y. G. Chen, Y. M. Wu, J. P. Avouac, Y. T. Kuo, Y. Wang, C. H. Chang, and K. C. Lin, 2009: The 2005 Ilan earthquake doublet and seismic crisis in northeastern Taiwan: Evidence for dyke intrusion associated with on-land propagation of the Okinawa Trough. Geophys. J. Int., 179, 678-686, doi: 10.1111/j.1365246X.2009.04307.x. [Link]

Lee, C. R., 1994: Compilation of the geothermal prospects data in Taiwan during 1966-1979. Bureau of Energy
Report, 500 pp.

Lee, C. S., G. G. Shor Jr, L. D. Bibee, R. S. Lu, and T. W. C. Hilde, 1980: Okinawa Trough: Origin of a back-arc basin. Mar. Geol., 35, 219-241, doi: 10.1016/00253227(80)90032-8. [Link]

Lee, C. Y., 1984: Subsurface Geological Report of the CPCCS-12T Geothermal well (Work Over) in the Chingshui Area, Ilan, Taiwan Petroleum Exploration Division, 1-7.

Lee, J. C., J. Angelier, and H. T. Chu, 1997: Polyphase history and kinematics of a complex major fault zone in the northern Taiwan mountain belt: The Lishan Fault. Tectonophysics, 274, 97-115, doi: 10.1016/S00401951(96)00300-9. [Link]

Lin, C. W. and W. H. Lin, 1995: Geologic map and explanatory text of Taiwan 15 Sanshin. Geological map of Taiwan scale 1:50,000, Central Geological Survey, Ministry of Economic Affairs, Taiwan. (in Chinese)

Lin, C. W. and C. N. Yang, 1999: Structural styles of the slate and schist belts in northeastern Taiwan. Bull. Cent. Geol. Surv., 12, 39-62. (in Chinese)

Shyu, J. B. H., K. Sieh, Y. G. Chen, and C. S. Liu, 2005: Neotectonic architecture of Taiwan and its implications for future large earthquakes. J. Geophys. Res., 110, B08402, doi: 10.1029/2004JB003251. [Link]

Sibuet, J. C., J. Letouzey, F. Barbier, J. Charvet, J. P. Foucher, T. W. C. Hilde, M. Kimura, C. Ling-Yun, B. Marsset, C. Muller, and J. F. Stéphan, 1987: Back arc extension in the Okinawa Trough. J. Geophys. Res., 92, 14041-14063, doi: 10.1029/JB092iB13p14041. [Link]

Sibuet, J. C., B. Deffontaines, S. K. Hsu, N. Thareau, J. P. Le Formal, C. S. Liu, J. Angelier, J. Y. Collot, S. Dominguez, M. Foumier, S. Lallemand, C. Y. Lu, J. Malavieille, P. Schnürle, and C. Wang, 1998: Okinawa trough backarc basin: Early tectonic and magmatic evolution. J. Geophys. Res., 103, 30245-30267, doi: 10.1029/98JB01823. [Link]

Su, F. C., 1978: Resistivity survey in the Chingshui prospect, Ilan, Taiwan. Petrol. Geol. Taiwan, 15, 255-263.

Tong, L. T., S. Ouyang, T. R. Guo, C. R. Lee, K. H. Hu, C. L. Lee, and C. J. Wang, 2008: Insight into the geothermal structure in Chingshui, Ilan, Taiwan. Terr. Atmos. Ocean. Sci., 19, 413-424, doi: 10.3319/ TAO.2008.19.4.413(T). [Link]

Torng, P. K. and C. S. Young, 1978: Subsurface Geological Report of the CPC-CS-13T Geothermal well in the Chingshui Geothermal District, I-lan, Taiwan Petroleum Exploration Division, 1-17.

Tseng, C. S., 1978: Geology and geothermal occurrence of the Chingshui and Tuchang districts, Ilan. Petrol. Geol. Taiwan, 15, 11-23. (in Chinese)

Wu, Y. J. and B. T. Chang, 1976: The geology of the Chingshui and Tuchang geothermal area and surrounding region. Min. Tech., 14, 484-489. 
Zhang, J. W., 2010: Detecting the basement and the faults under the Ilan plain, northeastern Taiwan, using seismic reflection method. Master Thesis, National Central University, Taiwan, 104 pp.
Zhou, B. and T. Dahlin, 2003: Properties and effects of measurement errors on 2D resistivity imaging surveying. Near Surf. Geophys., 1, 105-117, doi: 10.3997/18730604.2003001. [Link] 